\title{
Use of a thin liquid film moving under the action of gas flow in a mini-channel for removing high heat fluxes
}

\author{
Dmitry Zaitsev ${ }^{1,2}$, Egor Tkachenko ${ }^{1,3}$, Evgeniy Orlik ${ }^{1}$, and Oleg Kabov ${ }^{1,3, *}$ \\ ${ }^{1}$ Institute of Thermophysics SB RAS, 630090, Novosibirsk, Russia \\ ${ }^{2}$ National Research Tomsk Polytechnic University, 634050, Tomsk, Russia \\ ${ }^{3}$ Novosibirsk State University, 630090, Novosibirsk, Russia
}

\begin{abstract}
Intensively evaporating liquid films shear-driven in a mini- or micro-channel under the action of cocurrent gas flow are promising for the use in modern cooling systems of semiconductor devices. In this work, we investigated the influence of liquid and gas flow rates on the critical heat flux in a locally heated film of water, moving under the action of air flow in a mini-channel. In experiments a record value of critical heat flux of 870 $\mathrm{W} / \mathrm{cm}^{2}$ was reached. Heat spreading into the substrate and heat losses to the atmosphere in total do not exceed $25 \%$ at heat fluxes above 400 $\mathrm{W} / \mathrm{cm}^{2}$. A comparison with the critical heat flux for water flow boiling in the channel shows that, for shear-driven liquid films the critical heat flux is almost an order of magnitude higher.
\end{abstract}

\section{Introduction}

The development of modern microelectronic equipment requires efficient cooling systems, as it is necessary to remove high heat fluxes, up to $1 \mathrm{~kW} / \mathrm{cm}^{2}$, from local areas of the processor [1]. Thin and ultrathin (less than $10 \mu \mathrm{m}$ ) liquid films moving under the action of forced gas flow in mini-channels are promising for the use in thermal control systems of modern semiconductor devices [2]. Works [3-5] established the basic laws of flow and crisis phenomena in the liquid film, moving under the action of gas flow in a horizontal mini-channel under local heating. First experiments with shear-driven liquid films showed that such films are less prone to thermocapillary rupture than the ones moving under the action of gravity. This is because the film rupture and the formation of dry spots can be controlled by the gas flow. As a result, the critical heat flux for shear-driven liquid films can be several times higher than that for falling liquid films. In works [6-7] it is found, that in two phase flows in rectangular channels the stratified flow sub-regime, when a very thin liquid film is moving along the channel walls under the action of cocurrent gas flow, can exist for the channel heights as small as $100 \mu \mathrm{m}$ and less. Authors of [8] propose an efficient way of reduction of the viscous resistance in two-phase flows in micro-channels. All these studies confirm the prospects of using shear-driven liquid films for cooling of microsystems with high heat generation. The present paper presents new experimental data

* Corresponding author: kabov@,tpu.ru 
proving that shear-driven liquid films are capable to remove heat fluxes as high as 870 $\mathrm{W} / \mathrm{cm}^{2}$ from a heat source of $1 \times 1 \mathrm{~cm}^{2}$.

\section{Experimental setup}

Figure 1 shows the design of the test section. Its main part is a stainless steel plate with a pressed-in copper rod. The rod surface has a shape of a square head $1 \times 1 \mathrm{~cm}^{2}$, imitating the surface of a computer chip. The rod is heated using a nichrome coil, wound around its lower part. This design of the heater provides constant temperature on the surface of the rod, $\mathrm{T}_{\mathrm{w}}=$ const (as confirmed by thermocouple measurements). The work area is covered with a transparent cover of optical glass (not shown in Fig. 1), thus forming a flat channel. The channel height is $1.0-1.2 \mathrm{~mm}$, and the width is $40 \mathrm{~mm}$.

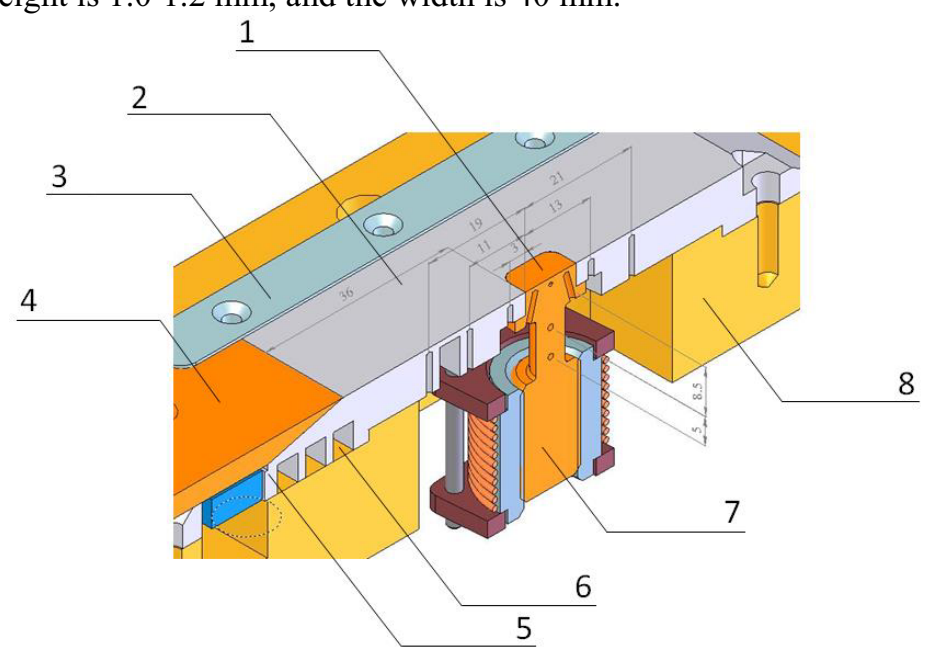

Fig. 1. The scheme of the test section: 1 - source of local heating; 2 - stainless steel plate; 3 channel height regulator; 4 - knife; 5 - liquid nozzle; 6 - thermal stabilizer; 7 - copper rod; 8 textolite plate. Locations and distances for thermocouples are shown.

Gas is introduced into the work area from a compressor. The fluid is supplied from the thermostat, enters the channel through the liquid nozzle and moves over the stainless steel plate as a film under the influence of gas friction. After passing the work area the gas is vented to atmosphere, and the fluid flows back to the thermostat. Distilled water with initial temperature of $24{ }^{\circ} \mathrm{C}$ is used as the working fluid. Air with temperature of $24-27^{\circ} \mathrm{C}$ and relative humidity of $15-30 \%$ is used as working gas.

Thermocouples, embedded in the stainless steel plate and the copper rod, allow determining the temperature of the working surface. Heat flux is determined via the electric power, generated on the heating coil. The thermal conductivity of copper is $400 \mathrm{~W} / \mathrm{mK}$, which more than an order exceeds the one of stainless steel $(15 \mathrm{~W} / \mathrm{mK})$; this provides moderate heat spreading from the heater to the steel plate. On the evaluation using measurements of thermocouples embedded in the steel plate, the heat spreading into the plate is not more than $15 \%$ when $\mathrm{q}>200 \mathrm{~W} / \mathrm{cm}^{2}$. To reduce heat losses to the atmosphere, the heater was wrapped with a layer of insulating material (not shown in Fig. 1). On evaluations using measurements of thermocouples embedded along the copper rod, the heat losses to the atmosphere does not exceed $10 \%$ at $\mathrm{q}>400 \mathrm{~W} / \mathrm{cm}^{2}$. Therefore, the heat spreading into the steel plate and heat losses to the atmosphere in total do not exceed $25 \%$ at $\mathrm{q}>400 \mathrm{~W} / \mathrm{cm}^{2}$. 


\section{Results}

This work studies the behavior of the liquid film, moving under the action of the gas at local heating, at different values of heat flux $q=0-870 \mathrm{~W} / \mathrm{cm}^{2}$, Reynolds number of the liquid $\mathrm{Re}_{1}=8.5-113$ and superficial gas velocity in the channel $\mathrm{U}_{\mathrm{Sg}}=3.8-93 \mathrm{~m} / \mathrm{s}$. Figure 2 illustrates the process of film rupture with the increase in heat flux at $\operatorname{Re}_{1}=30$ and $\mathrm{U}_{\mathrm{Sg}}=30$ $\mathrm{m} / \mathrm{s}$. At a certain threshold value of the heat flux the film disrupts with the formation of dry spots on the substrate. As a rule, initially dry areas are formed below the heater, along its side edges (Fig. 2a). Here we deal with thermocapillary film rupture, since dry patches initiate at temperatures well below the saturation temperature (the heater wall temperature is indicated at the capture of photos in Fig. 2). Thermocapillary tangential stresses at the film surface, induced by the dependence of the liquid surface tension on the temperature, and tangential stresses, induced by the flowing gas, are the main competitive forces at the gas-liquid interface. The film is thinnest along the lateral edges of the heater where temperature gradient at the film surface attains its maximum values. Film rupture is most likely to occur in this area. At a slightly higher heat flux, dry areas appear on the heater. With a further increase of the heat flux the heater is covered with metastable intensively evaporating thin liquid film with rapidly appearing and disappearing small dry spots (Fig. 2b). Upon reaching the critical heat flux, the heater suddenly dries up, and its temperature begins to increase sharply (Fig. 2c).

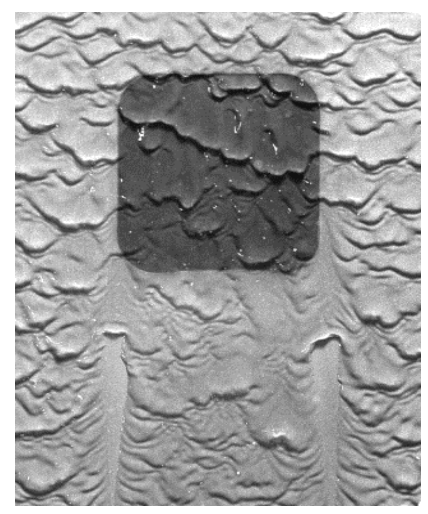

a) $\mathrm{q}=112 \mathrm{~W} / \mathrm{cm}^{2}, \mathrm{~T}_{\mathrm{w}}=84^{\circ} \mathrm{C}$

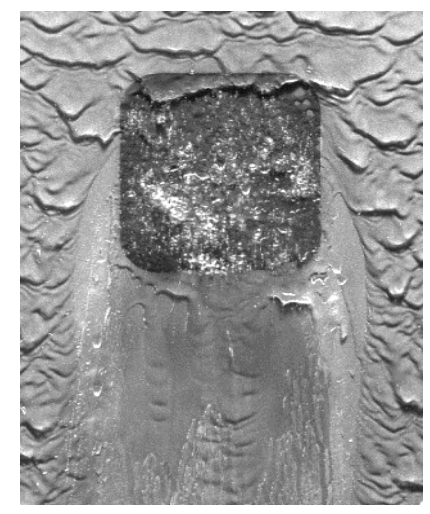

b) $\mathrm{q}=342 \mathrm{~W} / \mathrm{cm}^{2}, \mathrm{~T}_{\mathrm{w}}=129^{\circ} \mathrm{C}$

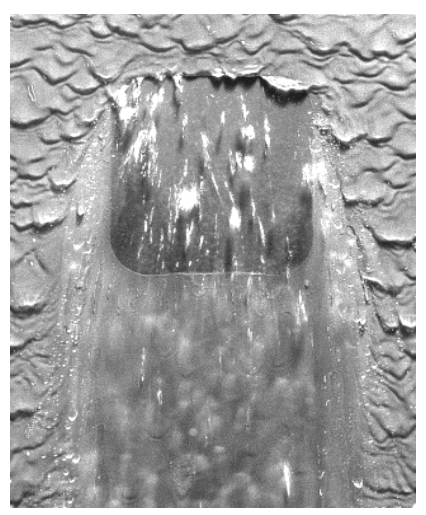

c) $\mathrm{q}=\mathrm{CHF}=375 \mathrm{~W} / \mathrm{cm}^{2}$, crisis

Fig. 2. Rupture and crisis in a water film moving under the action of the gas flow; the heater is $1 \mathrm{x} 1$ $\mathrm{cm}^{2}$, the channel height is $1.2 \mathrm{~mm}, \mathrm{Re}_{1}=30, \mathrm{U}_{\mathrm{Sg}}=30 \mathrm{~m} / \mathrm{s}$, the flow is directed top-down.

Figure 3 shows data obtained on the critical heat flux depending on Reynolds number of liquid and superficial gas velocity. It is seen that with increasing Reynolds number of the liquid and superficial gas velocity, the critical heat flux increases. In experiments, a record value of critical heat flux $870 \mathrm{~W} / \mathrm{cm}^{2}$ was reached (Fig. 3, point $\operatorname{Re}_{1}=113, U_{S g}=71 \mathrm{~m} / \mathrm{s}$ ). This critical heat flux for water film moving under the action of the gas flow was achieved at a mass flow rate of water $100 \mathrm{~kg} / \mathrm{m}^{2} \mathrm{~s}$. In this case, as shown in [9], the critical heat flux for subcooled water boiling in the mini-channel at the same mass flow rate of liquid (at atmospheric pressure and subcooling to the saturation temperature of $75 \mathrm{~K}$ ) reaches a value $90 \mathrm{~W} / \mathrm{cm}^{2}$ (Fig. 3, line 7). According to [9], to reach a heat flux of $870 \mathrm{~W} / \mathrm{cm}^{2}$ at water flow boiling in the mini-channel the mass flow rate of the liquid shall be $5000 \mathrm{~kg} / \mathrm{m}^{2} \mathrm{~s}$, which 50 times exceeds the mass flow rate in our experiment. Fig. 3 also presents data on the critical heat flux for water pool boiling (formula of Kutateladze, line 5) as well as for water pool boiling at subcooling to the saturation temperature of $75 \mathrm{~K}$ (line 6) [10]. 


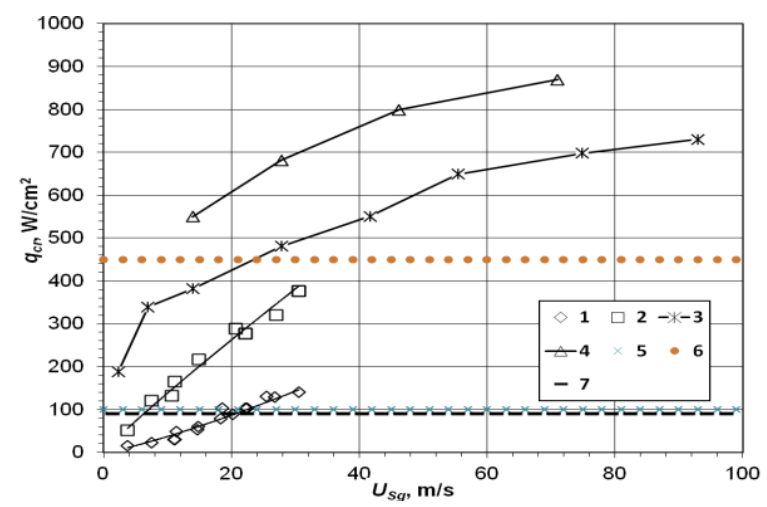

Fig. 3. Dependence of the critical heat flux on superficial gas velocity, $U_{\mathrm{Sg}}$, Reynolds number of the liquid $\mathrm{Re}_{1}$, and the channel height $\mathrm{H} .1-\mathrm{Re}_{1}=8.5, \mathrm{H}=1.2 \mathrm{~mm} ; 2-\mathrm{Re}_{1}=30, \mathrm{H}=1.2 \mathrm{~mm} ; 3-\mathrm{Re}_{1}=$ $62, \mathrm{H}=1.0 \mathrm{~mm} ; 4-\mathrm{Re}_{1}=113, \mathrm{H}=1.0 \mathrm{~mm} ; 5$ - water pool boiling (formula of Kutateladze $\left.q_{c r}=0.14 r \sqrt{\rho_{v}} \sqrt[4]{\sigma g\left(\rho_{1}-\rho_{v}\right)},[10]\right) ; 6$ - water pool boiling at subcooling to the saturation temperature of $75 \mathrm{~K}$ [10]; 7 - water flow boiling in a mini-channel for mass flow rate $100 \mathrm{~kg} / \mathrm{m}^{2} \mathrm{~s}$, at atmospheric pressure and subcooling to the saturation temperature of $75 \mathrm{~K}$ [9].

\section{Conclusion}

The critical heat flux for thin water films, moving under the friction of gas flow, is almost an order of magnitude higher than that for pool boiling and flow boiling in the channel. In the experiments, the record value of the critical heat flux of $870 \mathrm{~W} / \mathrm{cm}^{2}$ for thin film flows was reached. This confirms the prospects of using the shear-driven liquid films in modern cooling systems of semiconductor devices with high local heat generation. Total heat losses to the atmosphere and heat spreading into the substrate in our experiments do not to exceed $25 \%$ at heat fluxes higher than $400 \mathrm{~W} / \mathrm{cm}^{2}$.

This work was supported by the Ministry of Education and Science of Russia (Agreement No 14.604.21.0053, project identifier RFMEFI60414X0053).

\section{References}

1. A. Bar-Cohen, P. Wang, ASME. J. Heat Transf. 134, 051017 (2012)

2. O.A. Kabov, Yu.V. Lyulin, I.V. Marchuk and D.V. Zaitsev, Int. J. Heat Fluid Flow 28, 103 (2007)

3. D.V. Zaitsev, D.A. Rodionov and O.A. Kabov, Tech. Phys. Lett. 35, 680 (2009)

4. O.A. Kabov and D.V. Zaitsev, Multiphase Sci. Tech. 21, 249 (2009)

5. O.A. Kabov, D.V. Zaitsev, V.V. Cheverda, A. Bar-Cohen, Exp. Therm. Fluid Sci. 35, $825(2011)$

6. E.A. Chinnov, F.V. Ronshin, O.A. Kabov, Int. J. Aip. Conf. Proc. 80, 57 (2016)

7. E.A. Chinnov, F.V. Ronshin, O.A. Kabov, Interfacial Phenomena and Heat Transfer 3, 243 (2015)

8. E.Ya. Gatapova, V.S. Ajaev, O.A. Kabov, JETP Letters 101, 160 (2015)

9. W. Zhang, T. Hibiki, K. Mishima, Y. Mi, Int. J. Heat Mass Tran. 49, 1058 (2006)

10. S.S. Kutateladze, Heat Transfer in Condensation and Boiling (Mashgiz, Moscow, 1952) 